\title{
Development of Activated Carbon from Cotton Fibre Waste as Potential Mercury Adsorbent: Kinetic and Equilibrium Studies
}

\author{
Jatindra N. Bhakta, ${ }^{1,2}$ Piyali Bhakta Majumdar, ${ }^{2}$ and Yukihiro Munekage ${ }^{2}$ \\ ${ }^{1}$ International Centre for Ecological Engineering, University of Kalyani, Kalyani, West Bengal 741 235, India \\ ${ }^{2}$ Department of Environmental Engineering, Faculty of Agriculture, Kochi University, B200, Monobe, Nankoku, Kochi 783-8502, Japan \\ Correspondence should be addressed to Jatindra N. Bhakta; lsnjbhakta@gmail.com
}

Received 23 November 2013; Accepted 17 December 2013; Published 5 February 2014

Academic Editor: Jean-Pierre Corriou

Copyright (c) 2014 Jatindra N. Bhakta et al. This is an open access article distributed under the Creative Commons Attribution License, which permits unrestricted use, distribution, and reproduction in any medium, provided the original work is properly cited.

\begin{abstract}
The study attempted to develop the activated carbon of cotton fibre (ACCF) from cotton waste as a high $\mathrm{Hg}^{2+}$ adsorbent media and characterize physicochemical properties using scanning electron microscopy coupled with energy dispersive spectroscopy (SEM-EDS) and $\mathrm{Hg}^{2+}$ adsorption kinetic by batch adsorption study with the function of contact time, solution $\mathrm{pH}$, dosages of ACCF, and Hg concentration. The SEM-EDS study revealed that ACCF is composed of carbon (95.1\%) and phosphorus pentoxide (4.9\%). Obtained results of adsorption kinetics showed that $15 \mathrm{~min}$ of contact time is required to achieve the equilibrium state and wide range of $\mathrm{pH}(4.08-7)$ is favourable for maximum $\mathrm{Hg}$ adsorption. The $\mathrm{Hg}^{2+}$ adsorption capacity showed a decreasing trend with increasing dose of ACCF, whereas a reverse response of adsorption capacity was pronounced with increasing $\mathrm{Hg}$ concentration. The data was well described by Freundlich isotherm model and determined the high $\mathrm{Hg}^{2+}$ adsorption capacity of ACCF (169.2 mg/g). To our knowledge, the application of ACCF in removing $\mathrm{Hg}^{2+}$ is the first study. $\mathrm{High}_{\mathrm{Hg}}{ }^{2+}$ adsorption capacity, economic feasibility, availability of cotton fibre waste, and simple preparation method concluded that it could be used as a novel low-cost and environmentally sound adsorbent media for removing high rate of $\mathrm{Hg}^{2+}$ from aqueous phase.
\end{abstract}

\section{Introduction}

Mercury $(\mathrm{Hg})$ is one of the top ten most toxic and hazardous pollutants in the Priority List of Hazardous Substances [1] for causing serious human and environmental health risks by bioconcentration, bioaccumulation, and biomagnification phenomena. $\mathrm{Hg}$ and its derivatives can be adsorbed through the gastrointestinal tract, skin, and lungs and hence it is recognized as dangerous and insidious poisons [2]. The monomethylmercury $\left(\mathrm{MeHg}^{+}\right)$or dimethylmercury $\left(\mathrm{Me}_{2} \mathrm{Hg}\right)$ can penetrate through cell membranes within seconds and cross the blood-brain barrier, which results in the induction of serious carcinogenic, mutagenic, teratogenic, tyrosinemia, paralysis, serious neural, intestinal, and renal disorders in the organ systems. The toxic, nonmetabolic function, conversion of lower to higher toxic forms, bioaccumulation, and serious health disorders on animal systems are the significant criteria of $\mathrm{Hg}$ [2-5]. The severity of $\mathrm{Hg}$ toxicity was recognized in the late 1950s and 1960s because of an environmental tragedy in Minamata Bay, Japan, where hundreds of individuals suffered from mercury poisoning (Minamata disease) [6]. The US Environmental Protection Agency (EPA) estimated 630,000 newborns in America are at risk for unsafe levels of $\mathrm{Hg}$ exposure [7].

The major sources of $\mathrm{Hg}$ contamination in the environment are geogenic, anthropogenic, and reemitted $\mathrm{Hg}$ [8]. The geogenic sources are volcanic activity and weathering of rocks and the major industrial sources are coal burning, electronic, paper, pharmaceutical industries $[9,10]$ chlor-alkali, paint, pulp and paper, oil refinery, electrical, rubber processing, and fertilizer industries [11, 12]. In particular, the World Health Organization (WHO) reported that between 25,000 and 125,000 tons of $\mathrm{Hg}$ were released into the environment in 1976 [13]. To discharge heavy metals into the environment, the WHO set up various permissible limits. According to USA's Environmental Protection Agency (EPA) permissible limit of $\mathrm{Hg}$ in wastewater is nil; according to the WHO [14] the limit for mercury in drinking water is $0.001 \mathrm{mg} / \mathrm{L}$ and 
according to the Bureau of Indian Standards it is $0.01 \mathrm{mg} / \mathrm{L}$ for wastewater.

Due to indiscriminate discharge, environmental hazardous, and severe harmful impacts on life, it is necessary to remove $\mathrm{Hg}$ from wastewaters before they are discharged into the environment. In order to remove the $\mathrm{Hg}$ from water, the adopted common methods include sulfide precipitation, ion exchange, alum and iron coagulation, electrodialysis, ultrafiltration, activated carbon adsorption, and various biological processes. Activated carbon (AC) has been widely used as an important adsorbent to remove various pollutants especially $\mathrm{Hg}$ from wastewaters due to having their welldeveloped porous structure, large active surface area, and good mechanical properties [15-19]. The AC can be prepared from a variety of materials. Commercially available AC in the market derived from peat, lignite, and wood are expensive. Though varieties of AC have been developed recently from apricot stones, nut shells, grape seeds maize cobs, rice husk, coconut husk, wood almond, hazelnut shells, pine timber, pine scrap, and jute sticks to adsorb $\mathrm{Hg}$ from water, but many of them are costly and/or inaccessible and/or ineffective in the practical application. In this regard, therefore, the lowcost $\mathrm{Hg}$ adsorbent materials with easy application methods still have demand. So there is a need to produce low-cost AC that can be prepared following the simple process and applied to pollution control [20]. Some studies prepared AC from cheaper and readily available materials for $\mathrm{Hg}$ removal [12, 20-24].

Activated carbon fibres are a comparatively modern form of porous carbon material with a number of significant advantages over the more traditional powder or granular forms. These include high surface area and adsorption capacity, as well as very high rates of adsorption from the gas or liquid phase. Nabais et al. developed AC fibres by microwave heating from acrylic textile fibres [25]. The cotton stalk can be used to prepare AC by the processes of zinc chloride [26] and phosphoric acid [16] activation. Kawasaki et al. proposed that the low-cost fibrous AC can be produced, since cotton fiber retains its fibrous form under carbonization [27]. Though the study concerning the preparation of AC from the cotton fibre waste has been performed, its application as adsorbent media for removing the pollutants from water has not been executed so far. Besides, the disposal and incineration of cotton waste derived from the various modern anthropogenic activities is one of the troublesome problems in the environment by generating huge waste as well as green house gas $\mathrm{CO}_{2}$. From this point of view, the properly collection keeping in mind the environmental aspect of waste management and conversion of cotton fibre waste into high surface area containing adsorbent media with high adsorption capacity of various environmental pollutants may be a novel and emerging solution in this respect. Therefore, the purposes of the present study were to develop the AC of cotton fibre (ACCF) as a novel and potential $\mathrm{Hg}^{2+}$ adsorbent media from waste of cotton fibre and characterize the $\mathrm{Hg}^{2+}$ adsorption kinetic by batch adsorption study for application in removing high rate of $\mathrm{Hg}^{2+}$ from the aqueous phase.

\section{Materials and Methods}

2.1. Preparation of Activated Carbon of Cotton Fibre (ACCF). The AC of cotton fibre (ACCF) was prepared by the process of microwave assisted pyrolysis. Microwaves can be used to pyrolyze the carbon source $[25,26,28]$. Waste cotton (used for microbiological work) of the laboratory was collected, extensively washed under tap water to remove any particulate, and finally sprayed with distilled water. This washed cotton was dried in sunlight. To pyrolyze, the cotton fibre $(50 \mathrm{~g})$ was placed within a lidded porcelain cup which in turn was placed inside the multimode microwave and heated at $>500^{\circ} \mathrm{C}$ for $10 \mathrm{~min}$. The temperature of the carbon bed during microwave treatment was measured using an infrared optical pyrometer. Activated carbon manufacturing consists of a charring or carbonization step in which most of the noncarbon material (and much of the carbon) is volatilized by pyrolysis (usually between 500 and $750^{\circ} \mathrm{C}$ ) and usually weight (60 to $70 \%$ ) is lost [29-31]. The basic microstructure of the char with microporosity is formed around $500^{\circ} \mathrm{C}$ [31]. After cooling, the ACCF was crushed into powder and stored in a sealed glass container for using in different studies.

2.2. Physicochemical Properties of ACCF Adsorbent. The physical and chemical characterizations were carried out by capturing images of surface morphology and analyzing the chemical composition of the ACCF using scanning electron microscopy (SEM) with a jeol model equipment coupled with energy dispersive spectroscopy (EDS) facility (JSM-6500F, JEOL) in the Center for Advanced Marine Core Research, Kochi University, Japan, following the standard process [32].

2.3. Batch Adsorption Experiment. The effect of process parameters (contact time, $\mathrm{pH}$, dosage of ACCF adsorbent, and initial concentration of $\mathrm{Hg}$ ) on the $\mathrm{Hg}^{2+}$ adsorption property of ACCF were performed in $100 \mathrm{~mL}$ capped glass bottles following the batch operation mode. All experiments used the known volume $(50 \mathrm{~mL})$ of $\mathrm{Hg}$ solution with known concentration as adsorbate and known weight of ACCF as adsorbent. The $\mathrm{Hg}$ solution containing capped glass bottles were shaken by mechanical shaker at the rate of 150 excursion/min within a temperature controlled incubator at $25^{\circ} \mathrm{C}$.

The effects of contact times were determined maintaining the $0.15 \mathrm{mg} / \mathrm{L}$ initial concentration of $\mathrm{Hg}$ solution with $\mathrm{pH}$ 4.08 and $0.05 \mathrm{~g} / \mathrm{L}$ dosage of ACCF. The influences of different $\mathrm{pH}$ values (4.08, 5.08, 6.08, 7.0, 8.12, 10.04, and 11.98) of $\mathrm{Hg}$ solution were examined keeping $0.15 \mathrm{mg} / \mathrm{L}$ initial concentration of $\mathrm{Hg}$ solution and $0.05 \mathrm{~g} / \mathrm{L}$ dosage of ACCF. The effects of initial $\mathrm{Hg}$ concentrations were evaluated using 0.05 , $0.1,0.15,0.2,0.3$, and $0.4 \mathrm{mg} / \mathrm{L} \mathrm{Hg}$ solutions with $\mathrm{pH} 4.08$ and $0.05 \mathrm{mg} / \mathrm{L}$ dosage of ACCF, whereas the effects of ACCF dosages were determined using $0.0125,0.025,0.05,0.1,0.2$, and $0.5 \mathrm{~g} / \mathrm{L}$ of ACCF maintaining the $0.1 \mathrm{mg} / \mathrm{L}$ initial concentration of $\mathrm{Hg}$ solution with $\mathrm{pH}$ 4.08. Each experiment was performed at least twice following the identical conditions using controls of only $\mathrm{Hg}$ solution and adsorbent without $\mathrm{Hg}$ in solution. 

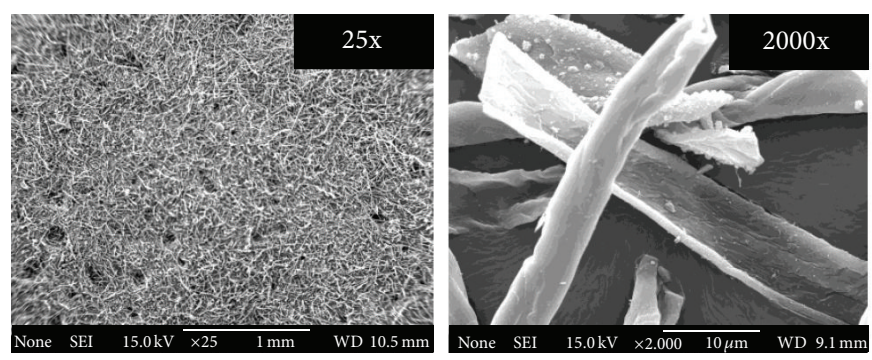

(a)
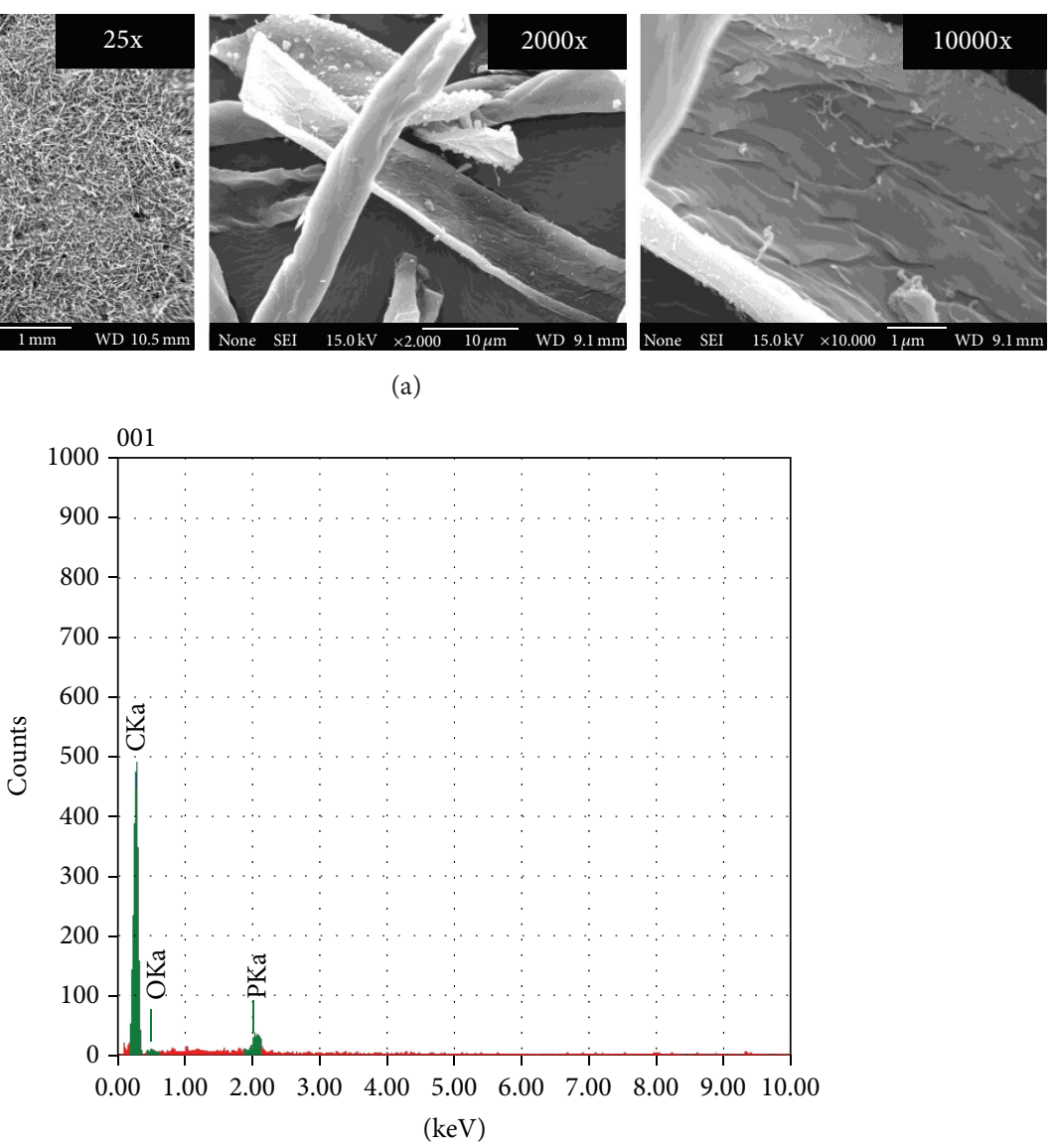

(b)

FIGURE 1: SEM macro- and microimages in three magnifying stages (25x, 2000x, and 10000x) (a) and EDS spectrum (b) of ACCF employed in the experiment.

The $\mathrm{Hg}^{2+}$ adsorption capacity $\left(q_{e}, \mathrm{mg} / \mathrm{g}\right)$ of ACCF at the equilibrium condition of the different experiments performed above was calculated following the mass balance relationship as

$$
q_{e}(\mathrm{mg} / \mathrm{g})=\left[\frac{C_{i}-C_{e}}{C_{i}}\right] \times V,
$$

where $C_{i}(\mathrm{mg} / \mathrm{L})$ and $C_{e}(\mathrm{mg} / \mathrm{L})$ are water-phase concentrations of $\mathrm{Hg}$ at the initial and the equilibrium states, respectively, $V(\mathrm{~L})$ is the volume of the $\mathrm{Hg}$ solution, and $M$ $(\mathrm{g})$ is the mass of ACCF.

The percentage of $\mathrm{Hg}$ removal from water phase was calculated using

$$
R_{e}(\%)=\left[\frac{C_{i}-C_{e}}{C_{i}}\right] \times 100,
$$

where $R_{e}$ is the percentage (\%) of $\mathrm{Hg}$ adsorbed and $C_{i}$ and $C_{e}$ are the initial and equilibrium concentrations of $\mathrm{Hg}(\mathrm{mg} / \mathrm{L})$ in the solution, respectively.

2.4. Hg Analysis. The water samples were collected and centrifuged and supernatant was used for analysis using the RA-3 Mercury Analyzer (Nippon Instruments Corporation, Japan). Hg removed from water was calculated by quantifying the residual $\mathrm{Hg}$ content in water phase.

\section{Results and Discussion}

3.1. Physicochemical Properties of ACCF. Figure 1(a) shows the SEM images of the developed ACCF adsorbent. These images displayed the morphological properties and megascopic and microscopic textures of the ACCF in three magnifying stages (25x, 2000x, and 10000x). Megascopic images (25x and 2000x) give the shape and size of the ACCF, whereas microscopic images (10000x) clearly showed the elaborated surface structure of the ACCF.

Figure 1(b) represents the EDS analysis for chemical composition of ACCF. The EDS data also exhibited that ACCF is composed of carbon (95.1\%) and phosphorus pentoxide (4.9\%). The large percentage of carbon constituent of ACCF indicating the availability of large surface area developed by microwave heating process, which is the important quality of an excellent adsorbent of AC. Generally, AC possesses an extraordinarily large surface area and pore volume that gives it a unique adsorption capacity [33]. 


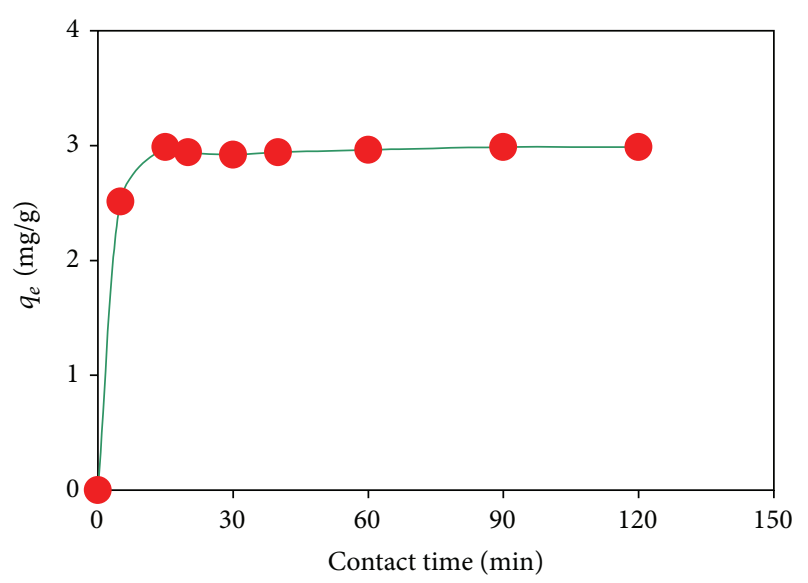

FigURE 2: Effect of contact time on $\mathrm{Hg}^{2+}$ adsorption of ACCF. (Initial concentration $0.15 \mathrm{mg} / \mathrm{L}$, ACCF dosage $0.0025 \mathrm{~g} / \mathrm{L}, \mathrm{pH} 4.08$, and contact time $120 \mathrm{~min}$ ).

\subsection{Hg Adsorption Kinetics of ACCF}

3.2.1. Effect of Contact Time ( $t$ ). The effects of contact times on the $\mathrm{Hg}^{2+}$ adsorption of ACCF from water phase were depicted in Figure 2. The ACCF showed a rapid adsorption rate of $\mathrm{Hg}^{2+}$ and equilibrium state of adsorption was achieved at 15 min contact period. The percentage of $\mathrm{Hg}^{2+}$ adsorption $(0-96.3 \%)$ increased with time and maximum percentage of adsorption was found at $15 \mathrm{~min}$. The equilibrium contact times of most of the adsorbent media are much higher than that of the ACCF. Therefore, it is pertinent to mention here that the ACCF achieved the equilibrium state within a narrow time period, which indicated its significantly rapid rate of $\mathrm{Hg}^{2+}$ adsorption properties that is helpful for treating the massive amount of $\mathrm{Hg}$ contaminated water within a short time span.

3.2.2. Effect of $p H$. Figure 3 elucidates the effects of initial $\mathrm{pH}$ of solution on the $\mathrm{Hg}^{2+}$ adsorption process of ACCF. The adsorption capacities $\left(q_{e}, 2.9-2.98 \mathrm{mg} / \mathrm{g}\right)$ exhibited a steady state from $\mathrm{pH} 4.08$ to 7 and sharply decreased (from 2.9 to $1.38 \mathrm{mg} / \mathrm{L}$ ) thereafter with increasing $\mathrm{pH}$. The percentage of $\mathrm{Hg}^{2+}$ adsorption varied from 44 to $96.7 \%$ and maximum adsorptions were recorded between $\mathrm{pH} 4.08$ and 7. It indicated that the $\mathrm{pH}$ plays an important role in the $\mathrm{Hg}^{2+}$ adsorption mechanism of ACCF and slightly acidic or neutral initial $\mathrm{pH}$ of solution (i.e., from 4.08 to 7 ) is optimum for adsorbing the maximum $\mathrm{Hg}^{2+}$ from water phase. It has been shown that $\mathrm{pH} 7$ is the optimum for $\mathrm{Hg}^{2+}$ adsorption [17] and highest arsenic adsorption was also reported at $\mathrm{pH}$ 7.5 [34] by AC and ceramic. The results also clearly signified that the developed ACCF can work efficiently in wide range of $\mathrm{pH}$. Activated carbon is also equally absorbent for both ionic and neutral species and is the most universal absorbent for complex mixtures of chemicals structures $[35,36]$. The strengths of $\mathrm{AC}$ as a poison antidote and water purification aid are its great absorption capacity, and its ability to absorb many chemicals with different structures [35]. Ion exchange

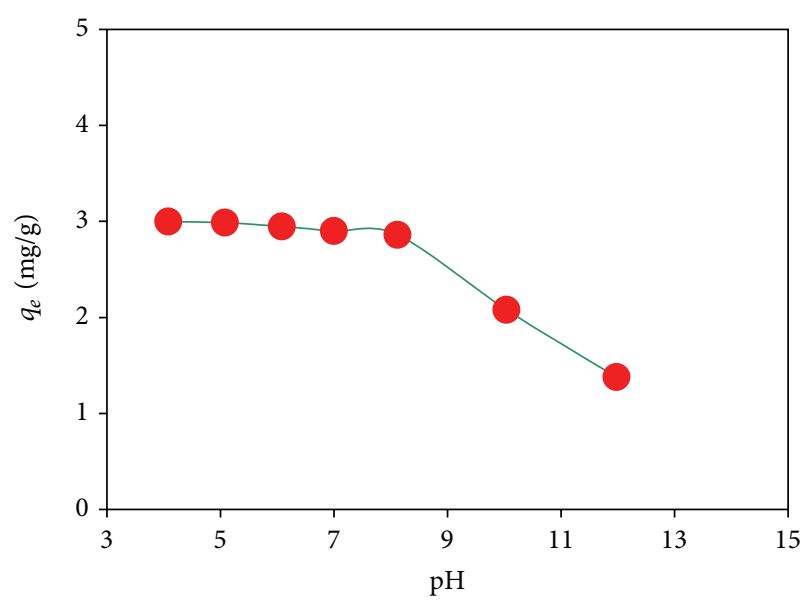

Figure 3: Effect of $\mathrm{pH}$ on the of $\mathrm{Hg}^{2+}$ adsorption of ACCF. (Initial concentration $0.15 \mathrm{mg} / \mathrm{L}$, contact time $15 \mathrm{~min}$, and ACCF dosage $0.0025 \mathrm{~g} / \mathrm{L})$.

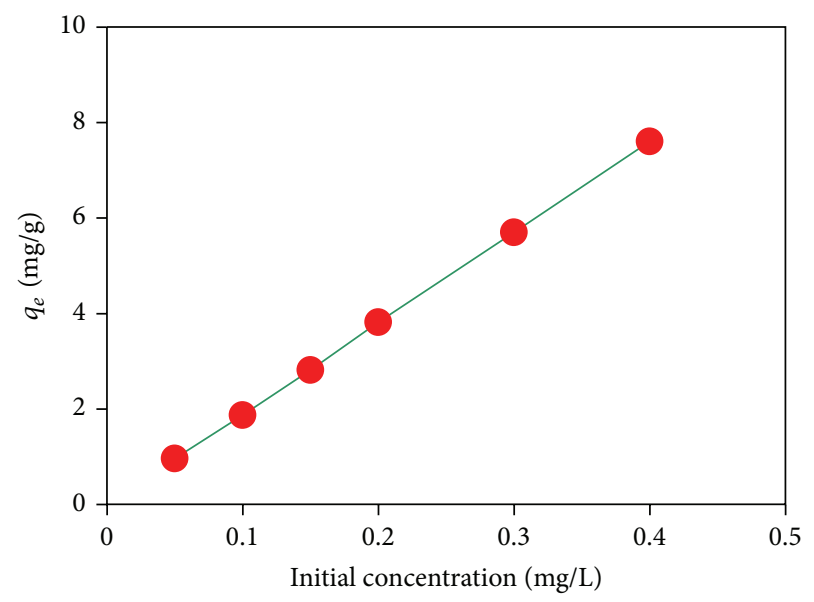

FIgURE 4: Effect of initial $\mathrm{Hg}$ concentration on the of $\mathrm{Hg}^{2+}$ adsorption of ACCF. (ACCF dosage $0.0025 \mathrm{~g} / \mathrm{L}, \mathrm{pH} 4.08$, and contact time $15 \mathrm{~min}$ ).

resins exist that are better absorbers than AC for either acidic or basic chemical species but not for neutral chemical species.

3.2.3. Effect of $\mathrm{Hg}$ Concentration $\left(C_{i}\right)$. The effect of initial $\mathrm{Hg}^{2+}$ concentrations on the adsorption process of ACCF was shown in Figure 4. The $\mathrm{Hg}^{2+}$ adsorption $\left(q_{e}, 0.9-7.6 \mathrm{mg} / \mathrm{g}\right)$ increased with increasing the initial $\mathrm{Hg}^{2+}$ concentration of solution. The maximum $\mathrm{Hg}$ adsorption percentage (96\%) was observed in the highest initial concentration $(0.4 \mathrm{mg} / \mathrm{L})$. The obtained results implied that the saturation rate of $\mathrm{Hg}^{2+}$ binding onto the functional groups of ACCF was greater in the higher concentrations by means of increasing electrostatic interactions which resulted in the increasing rate of adsorption.

3.2.4. Effect of Adsorbent Dosage ( $M)$. Figure 5 represents the effects of adsorbent dosages on the adsorption of $\mathrm{Hg}^{2+}$ onto 
the ACCF. The total amount of $\mathrm{Hg}^{2+}$ adsorption increased with increasing the dosages of ACCF, whereas the adsorption capacity $\left(q_{e}, 0.19-6.64 \mathrm{mg} / \mathrm{g}\right)$ of ACCF showed a reverse response with dosages. The percentage of adsorption varied from 83 to $99 \%$ in all dosages employed. The adsorption capacity and percentage were maximal at the dosages 0.0125 and $0.5 \mathrm{mg} / \mathrm{L}$, respectively. It has been proposed that the electrostatic interactions, interference between binding sites, and reduced mixing in higher densities of higher adsorbent doses are responsible for decreasing the adsorption capacity $\left(q_{e}, \mathrm{mg} / \mathrm{g}\right)$ with increasing adsorbent dosages [37, 38]. The obtained results are supported by the results of sequential adsorbent treatment using solid adsorbents (such as sand, silica, coal, and alumina) proposed by Yabe and de Oliveira [37].

3.3. Adsorption Isotherms. The adsorption phenomenon is usually studied through adsorption isotherm, which indicates the relationship of the amounts of adsorbate in the liquid phase adsorbed onto the surface of the adsorbent at the equilibrium condition at constant temperature. Adsorption isotherms are most commonly used to select the adsorbent or even the adsorption process as a unit operation for the adsorptive separation by evaluating the efficiency of an adsorbent. Thus, the adsorption isotherms are useful to design and optimize the adsorption systems [38, 39]. Generally, the Langmuir and the Freundlich equations are commonly used to evaluate such isotherm models. Therefore, the Langmuir isotherm and the Freundlich isotherm models have been studied to describe the data of adsorption experiments of present study, which show the different adsorption mechanisms. The present study considered these two isotherms using (3)-(4) [40] to describe the data obtained.

Equation (3) of the Langmuir adsorption isotherm is as below:

$$
\begin{gathered}
q_{e}=\frac{q_{m} b C_{e}}{1+b C_{e}}, \\
\frac{C_{e}}{q_{e}}=\frac{1}{b q_{m}}+\frac{C_{e}}{q_{m}},
\end{gathered}
$$

where $q_{e}$ is the mass of the contaminant adsorbed per unit weight of the adsorbent $(\mathrm{mg} / \mathrm{g}), C_{e}$ is the equilibrium concentration of the $\mathrm{Hg}$ in solution $(\mathrm{mg} / \mathrm{L}), q_{m}$ is the monolayer adsorption capacity $(\mathrm{mg} / \mathrm{g})$, and $b$ is the Langmuir constant related to the free energy of adsorption $(\mathrm{L} / \mathrm{mg})$. The Langmuir parameters and correlation coefficient were obtained by fitting the experimental data to the linearized equation derived from (3), which are represented in Table 1. The Langmuir adsorption isotherm assumes that adsorption takes place at definite points of attachment on the surface of the adsorbent and has found successful application too many sorption process of monolayer adsorption.

Equation (4) of the Freundlich isotherm is as follows:

$$
\begin{gathered}
q_{e}=K_{f} C_{e}^{1 / n}, \\
\log q_{e}=\log K_{f}+\frac{1}{n} \log C_{e},
\end{gathered}
$$

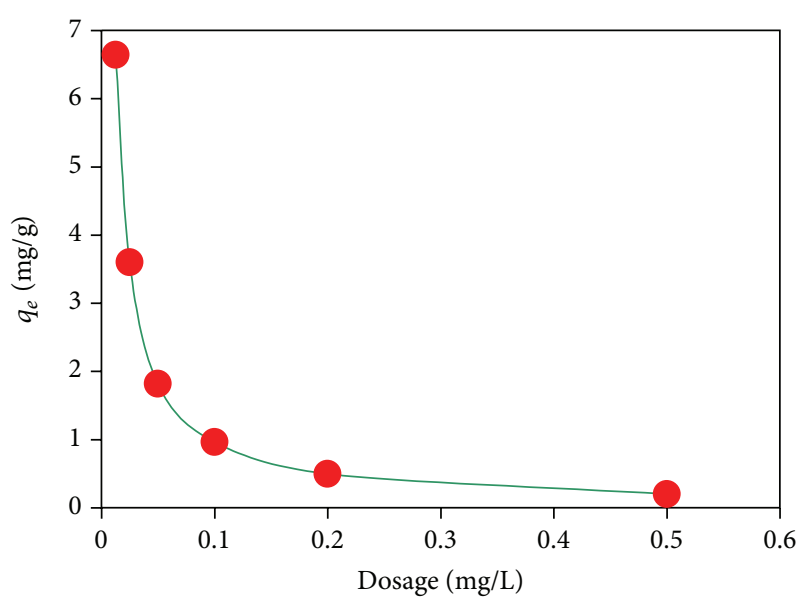

FIGURE 5: Effect of adsorbent dosage on the of $\mathrm{Hg}^{2+}$ adsorption of ACCF. (Initial concentration $0.15 \mathrm{mg} / \mathrm{L}, \mathrm{pH} 4.08$, and contact time $15 \mathrm{~min})$.

TABLE 1: Freundlich and Langmuir parameters for the $\mathrm{Hg}^{2+}$ adsorption of ACCF.

\begin{tabular}{lcccccc}
\hline Adsorbent & \multicolumn{3}{c}{ Freundlich } & \multicolumn{3}{c}{ Langmuir } \\
& $\begin{array}{c}K_{f} \\
(\mathrm{mg} / \mathrm{g})\end{array}$ & $1 / n$ & $R^{2}$ & $\begin{array}{c}q_{m} \\
(\mathrm{mg} / \mathrm{g})\end{array}$ & $\begin{array}{c}b \\
(\mathrm{~L} / \mathrm{mg})\end{array}$ & $R^{2}$ \\
\hline ACCF & 169.2 & 0.837 & 0.974 & 22.27 & 21.41 & 0.287 \\
\hline
\end{tabular}

where $q_{e}$ is the mass of the contaminant adsorbed per unit weight of the adsorbent $(\mathrm{mg} / \mathrm{g}), C_{e}$ is the equilibrium concentration of the cadmium in solution $(\mathrm{mg} / \mathrm{L}), K_{f}$ is the adsorption capacity of the Freundlich constant (mg/g), and $n$ is the adsorption intensity of Freundlich adsorption isotherm constant. The Freundlich adsorption parameters are shown in Table 1.

The $\mathrm{Hg}^{2+}$ adsorption isotherm of the ACCF is represented in Figure 6. The correlation coefficients of the Freundlich and the Langmuir models are 0.974 and 0.287 , respectively, which clearly demonstrated that the Freundlich isotherm is well fitted with the experimental data rather than the Langmuir isotherm and it cannot be mentioned about the monolayer coverage of $\mathrm{Hg}^{2+}$ ions on ACCF. The adsorption capacity $\left(K_{f}\right)$ is $169.2 \mathrm{mg} / \mathrm{g}$ which indicated that ACCF has high $\mathrm{Hg}^{2+}$ adsorption capacity. It is generally stated that the values of $n$ in the range of 1 to 10 represent good adsorption [41]. In this study, the Freundlich constant $n$ was 1.19, which also implyed the favorable adsorption. This high adsorption capacity is probably due to having high active surface area and well as unique electrical double layer of AC [42].

3.4. Management of Spent AC. The AC carbon does not itself appear on any of the lists of hazardous substances [43]. Activated carbon used to treat hazardous waste could be considered to be hazardous waste itself [44]. Though it was not considered here, the Hg loaded spent AC can be recycled, reactivated, or regenerated using thermal or hydrothermal methods to extract/recover Hg [45] from ACCF in order to avoid the further hazardous environmental problems. 


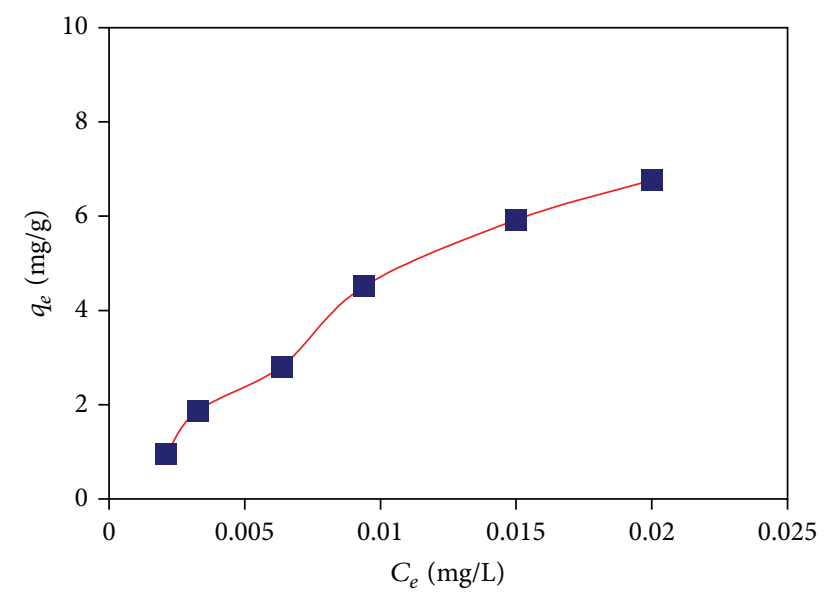

Figure 6: Equilibrium curve for the adsorption of $\mathrm{Hg}^{2+}$ on ACCF.

\section{Conclusions}

This study developed an AC of high $\mathrm{Hg}$ adsorbing capacity $(169.2 \mathrm{mg} / \mathrm{g})$ from cotton fibre waste using the microwave assisted heating process. The batch adsorption experiments clearly revealed the significant influence of various environmental process parameters on the $\mathrm{Hg}$ adsorption capacity of ACCF. The study proposed that contact time $15 \mathrm{~min}$ and wide range of $\mathrm{pH}(4.08-7)$ are to be optimal for maximum $\mathrm{Hg}$ adsorption. The results also showed an increasing Hg adsorption capacity of ACCF with increasing initial concentration of $\mathrm{Hg}$, whereas a reverse response of adsorption capacity was found in the effect of ACCF dosages. The adsorption isotherm determined that the resultant data of adsorption kinetic is well fitted with the Freundlich isotherm model which largely indicates its efficiency in practical field of application. The high surface area of ACCF is the major driving factor for adsorbing high amount of $\mathrm{Hg}$ from water phase. In spite of above properties, the economical feasibility, availability of waste cotton and simple preparation method concluded that it could be used as a novel low-cost adsorbent for removing $\mathrm{Hg}$ from water by converting the cotton waste into environmentally sound adsorbent media of AC with high $\mathrm{Hg}$ adsorbing capacity.

\section{Conflict of Interests}

The authors declare that there is no conflict of interests regarding the publication of this paper.

\section{Acknowledgments}

The authors are grateful to the Japan society for the promotion of science, Government of Japan for sponsoring the JSPS research Grant (no. 20380181) to carry out the present study. The authors express their sincere thanks to Dr. Yuhji Yamamoto and Md. Salim for extending his kind cooperation in the SEM-EDS analysis.

\section{References}

[1] ATSDR (Agency for Toxic Substances Disease Registry), "CERCLA priority list of hazardous substances," Agency for Toxic Substances and Disease Registry, Atlanta, Ga, USA, 2007, http://www.atsdr.cdc.gov/.

[2] P. C. Bidstrup, Toxicity of Mercury and Its Compounds, Elsevier, Amsterdam, The Netherlands, 1964.

[3] R. Eisler, "Mercury hazards to fish, wildlife, and invertebrates: a synoptic review," U.S. Fish and Wildlife Service Biological Report, vol. 85, pp. 1-10, 1987.

[4] M. Horvat, N. Nolde, V. Fajon et al., "Total mercury, methylmercury and selenium in mercury polluted areas in the province Guizhou, China," Science of the Total Environment, vol. 304, no. 1-3, pp. 231-256, 2003.

[5] F. Fang, Q. Wang, and J. Li, "Urban environmental mercury in Changchun, a metropolitan city in Northeastern China: source, cycle, and fate," Science of the Total Environment, vol. 330, no. 1-3, pp. 159-170, 2004.

[6] F. S. Zhang, J. O. Nriagu, and H. Itoh, "Mercury removal from water using activated carbons derived from organic sewage sludge," Water Research, vol. 39, no. 2-3, pp. 389-395, 2005.

[7] K. R. Mahaffey, "Methylmercury: epidemiology update," in Proceedings of the National Fish Forum, San Diego, Calif, USA, 2004, http://www.epa.gov/waterscience/fish/forum/2004/presentations/Monday/mahaffey.pdf.

[8] USEPA, "Mercury study report to congress," EPA-452/R-97-005, 1997.

[9] H. Biester, G. Müller, and H. F. Schöler, "Estimating distribution and retention of mercury in three different soils contaminated by emissions from chlor-alkali plants: part I," Science of the Total Environment, vol. 284, no. 1-3, pp. 177-189, 2002.

[10] F. M. G. Tack, T. Vanhaesebroeck, M. G. Verloo, K. van Rompaey, and E. van Ranst, "Mercury baseline levels in Flemish soils (Belgium)," Environmental Pollution, vol. 134, no. 1, pp. 173-179, 2005.

[11] K. A. Krishnan and T. S. Anirudhan, "Removal of mercury (II) from aqueous solutions and chlor-alkali industry effluent by steam activated and sulfurised activated carbons prepared from bagasse pith: kinetics and equilibrium studies," Journal of Hazardous Materials, vol. 92, no. 2, pp. 161-183, 2002.

[12] K. Kadirvelu, M. Kavipriya, C. Karthika, N. Vennilamani, and S. Pattabhi, "Mercury (II) adsorption by activated carbon made from sago waste," Carbon, vol. 42, no. 4, pp. 745-752, 2004.

[13] H. Kothandaraman and S. Geetha, Principle of Environmental Chemistry, B.I. Publication, New Delhi, India, 1997.

[14] WHO, Guidelines for Drinking Water Quality, vol. 1, 3rd edition, 2004.

[15] K. Gergova, N. Petrov, and V. Minkova, "A comparison of adsorption characteristics of various activated carbons," Journal of Chemical Technology and Biotechnology, vol. 56, no. 1, pp. 7782, 1993.

[16] B. S. Girgis and M. F. Ishak, "Activated carbon from cotton stalks by impregnation with phosphoric acid," Materials Letters, vol. 39, no. 2, pp. 107-114, 1999.

[17] J. N. Bhakta, M. Salim, K. Yamasaki, and Y. Munekage, "Mercury adsorption stoichiometry of ceramic and activated carbon from aqueous phase under different $\mathrm{pH}$ and temperature," $A R P N$ Journal of Engineering and Applied Sciences, vol. 4, no. 6, pp. 5259, 2009. 
[18] M. Zabihi, A. Ahmadpour, and A. H. Asl, "Removal of mercury from water by carbonaceous sorbents derived from walnut shell," Journal of Hazardous Materials, vol. 167, no. 1-3, pp. 230236, 2009.

[19] J. H. Cai and C. Q. Jia, "Mercury removal from aqueous solution using coke-derived sulfur-impregnated activated carbons," Industrial and Engineering Chemistry Research, vol. 49, no. 6, pp. 2716-2721, 2010.

[20] M. Streat, J. W. Patrick, and M. J. Camporro Perez, "Sorption of phenol and para-chlorophenol from water using conventional and novel activated carbons," Water Research, vol. 29, no. 2, pp. 467-472, 1995.

[21] S. S. Krishnan, A. Cancilla, and R. E. Jervis, "Waste water treatment for heavy metal toxins using plant and hair," Science of the Total Environment, vol. 68, no. 1, pp. 267-273, 1988.

[22] R. R. Navarro, K. Sumi, N. Fujii, and M. Matsumura, "Mercury removal from wastewater using porous cellulose carrier modified with polyethyleneimine," Water Research, vol. 30, no. 10, pp. 2488-2494, 1996.

[23] K. Kadirvelu, Preparation and characterization of coir pith carbon and its utilization in the treatment of metal bearing wastewater [Ph.D. thesis], Bharathiar University, Coimbatore, India, 1998

[24] C. X. Hu, J. S. Zhou, Z. Y. Luo, S. He, G. K. Wang, and K. F. Cen, "Effect of oxidation treatment on the adsorption and the stability of mercury on activated carbon," Journal of Environmental Sciences, vol. 18, no. 6, pp. 1161-1166, 2006.

[25] J. M. V. Nabais, P. J. M. Carrott, M. M. L. R. Carrott, and J. A. Menéndez, "Preparation and modification of activated carbon fibres by microwave heating," Carbon, vol. 42, no. 7, pp. 13151320, 2004.

[26] H. Deng, L. Yang, G. Tao, and J. Dai, "Preparation and characterization of activated carbon from cotton stalk by microwave assisted chemical activation-application in methylene blue adsorption from aqueous solution," Journal of Hazardous Materials, vol. 166, no. 2-3, pp. 1514-1521, 2009.

[27] N. Kawasaki, H. Tominaga, F. Ogata, K. Inoue, and M. Kankawa, "Development of novel carbon fiber produced from waste fiber by carbonization," Journal of Oleo Science, vol. 61, no. 10, pp. 593-600, 2012.

[28] K. M. Holland, "Producing active carbon using microwave discharge," US Patent \#5, 364, 821, 1994.

[29] J. Sun, E. J. Hippo, H. Marsh, W. S. O’Brien, and J. C. Crelling, "Activated carbon produced from an Illinois basin coal," Carbon, vol. 35, no. 3, pp. 341-352, 1997.

[30] J. Díaz-Terán, D. M. Nevskaia, A. J. López-Peinado, and A. Jerez, "Porosity and adsorption properties of an activated charcoal," Colloids and Surfaces A, vol. 187-188, pp. 167-175, 2001.

[31] S. M. Manocha, "Porous carbons," Sadhana, vol. 28, part 1-2, pp. $335-348,2003$.

[32] J. N. Bhakta and Y. Munekage, "Identification of potential soil adsorbent for the removal of hazardous metals from aqueous phase," International Journal of Environmental Science and Technology, vol. 10, pp. 315-324, 2013.

[33] F. S. Baker, C. E. Miller, A. J. Repik, and E. D. Tolles, "Activated carbon," in Kirk-Othmer Encyclopedia of Chemical Technology, vol. 4, pp. 1015-1037, John Wiley \& Sons, New York, NY, USA, 1992.

[34] M. Salim, Y. Munekage, and K. M. Naing, "Arsenic(III) removal from contaminated water using silica ceramic: a batch adsorption study," Journal of Applied Sciences, vol. 7, no. 16, pp. 23142320, 2007.
[35] D. O. Cooney, Activated Charcoal: Antidotal and Other Medical Uses, Marcel Dekker, New York, NY, USA, 1980.

[36] O. Vohler, F. von Sturm, E. Wege, H. von Kienle, M. Voll, and P. Kleischmit, "Carbon," in Ullmann's Encyclopedia of Industrial Chemistry, W. Gerhartz, Ed., VCH, Berlin, Germany, 5th edition, 1986.

[37] M. J. S. Yabe and E. de Oliveira, "Heavy metals removal in industrial effluents by sequential adsorbent treatment," Advances in Environmental Research, vol. 7, no. 2, pp. 263-272, 2003.

[38] B. Benguella and H. Benaissa, "Cadmium removal from aqueous solutions by chitin: kinetic and equilibrium studies," Water Research, vol. 36, no. 10, pp. 2463-2474, 2002.

[39] Y. Yalcnkaya, L. Soysal, A. Denizli, M. Y. Arca, S. Bektaş, and O. Genç, "Biosorption of cadmium from aquatic systems by carboxymethylcellulose and immobilized trametes versicolor," Hydrometallurgy, vol. 63, no. 1, pp. 31-40, 2002.

[40] H. Cesur and N. Balkaya, "Zinc removal from aqueous solution using an industrial by-product phosphogypsum," Chemical Engineering Journal, vol. 131, no. 1-3, pp. 203-208, 2007.

[41] Y. H. Magdy and A. A. M. Daifullah, "Adsorption of a basic dye from aqueous solutions onto sugar-industry-mud in two modes of operations," Waste Management, vol. 18, no. 4, pp. 219-226, 1998.

[42] J. S. Mattson and H. B. Mark Jr., Activated Carbon, Marcel Dekker, New York, NY, USA, 1971.

[43] USSPA, EPCRA Section 313 Reporting Guidance for Food Processors, EPA Office of Pollution Prevention and Toxics, Washington, DC, USA, 1998.

[44] M. H. Shapiro, "How treating filtration media comparable to activated carbon would be permitted under RCRA," Letter to S. M. Churbock (Envirotrol), USEPA, Washington, DC, USA, 1996, http://yosemite.epa.gov/osw/rcra.nsf/documents/ 3A7C832687A92576852565DA006F05D9.

[45] M. D. Sufnarski, The Regeneration of Granular Activated Carbon Using Hydrothermal Technology, The University of Texas, Austin, Tex, USA, 1999, http://www.dtic.mil/get-tr-doc/ pdf?AD=ADA362534. 

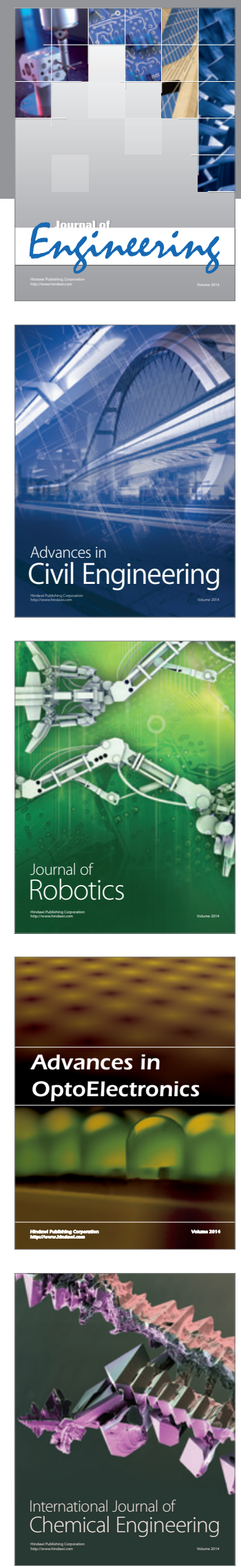

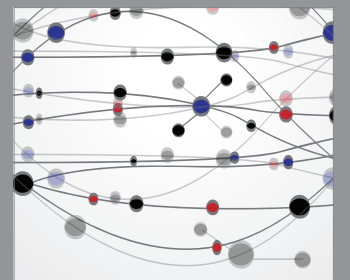

The Scientific World Journal
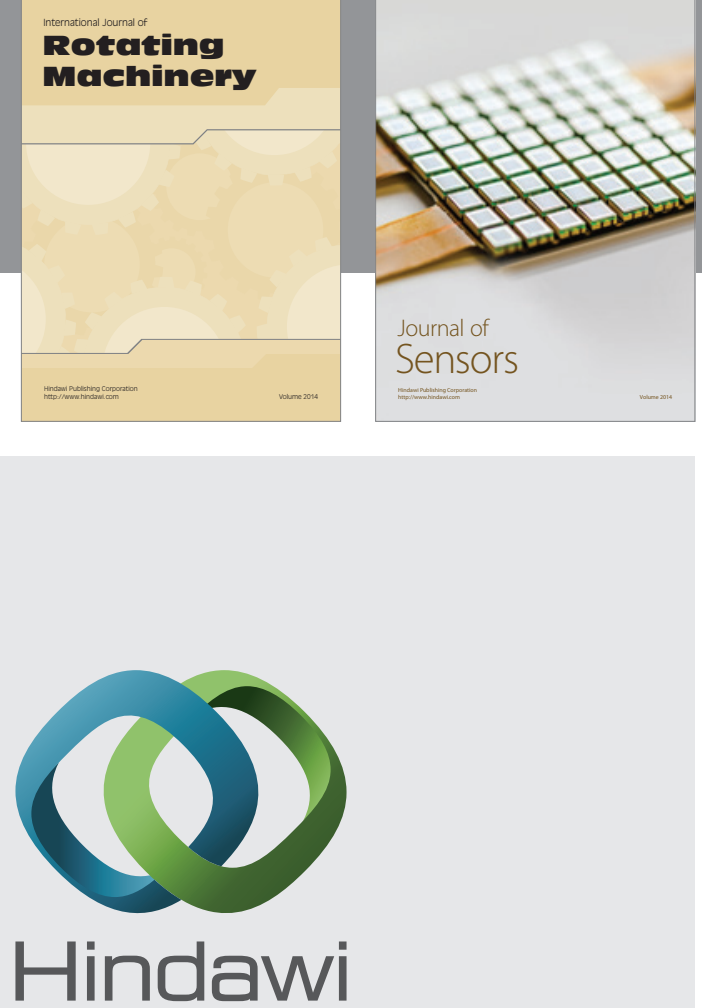

Submit your manuscripts at http://www.hindawi.com
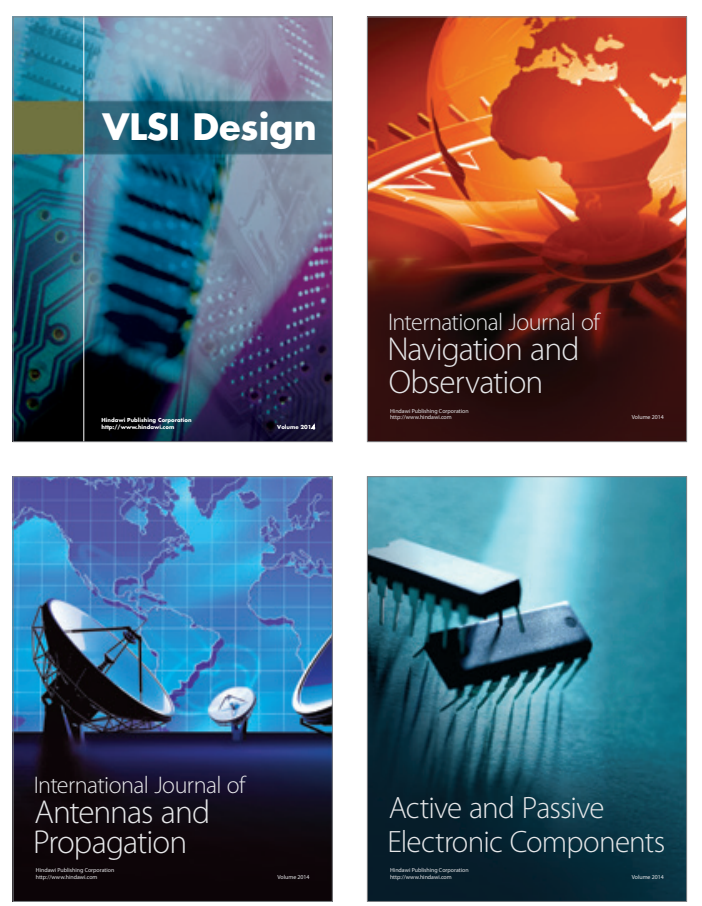
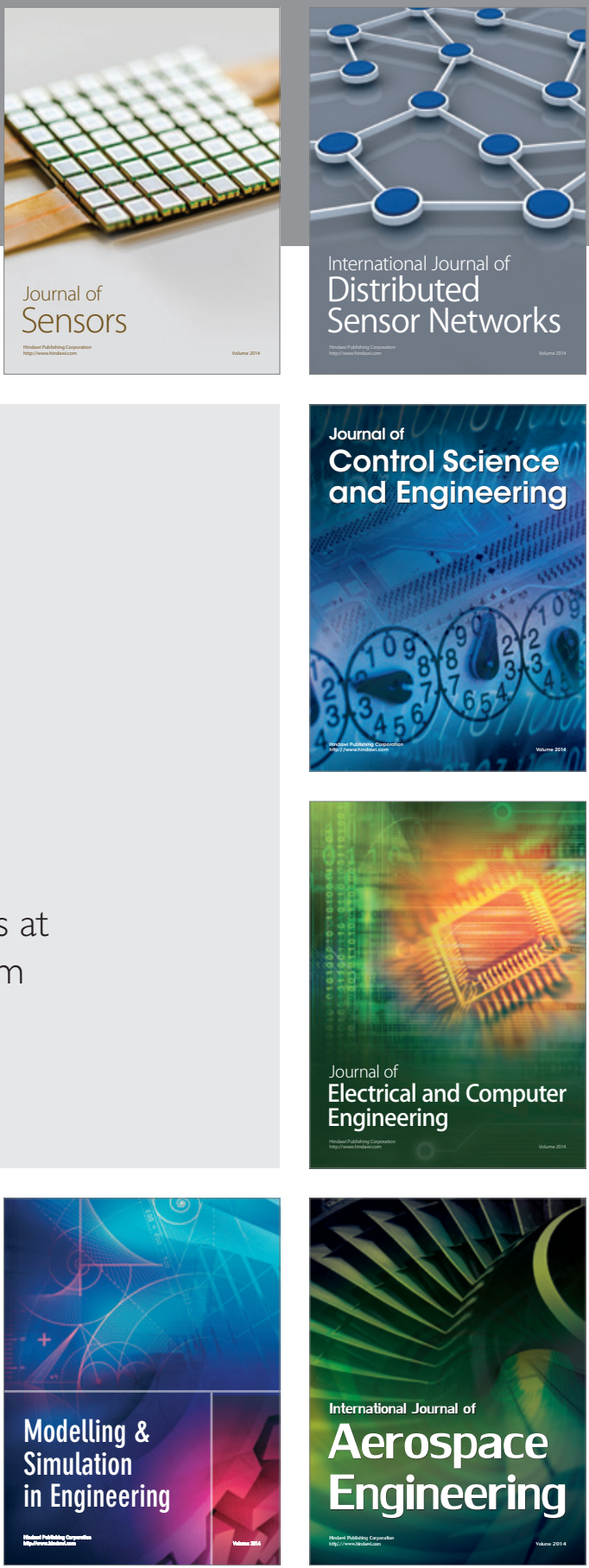

Journal of

Control Science

and Engineering
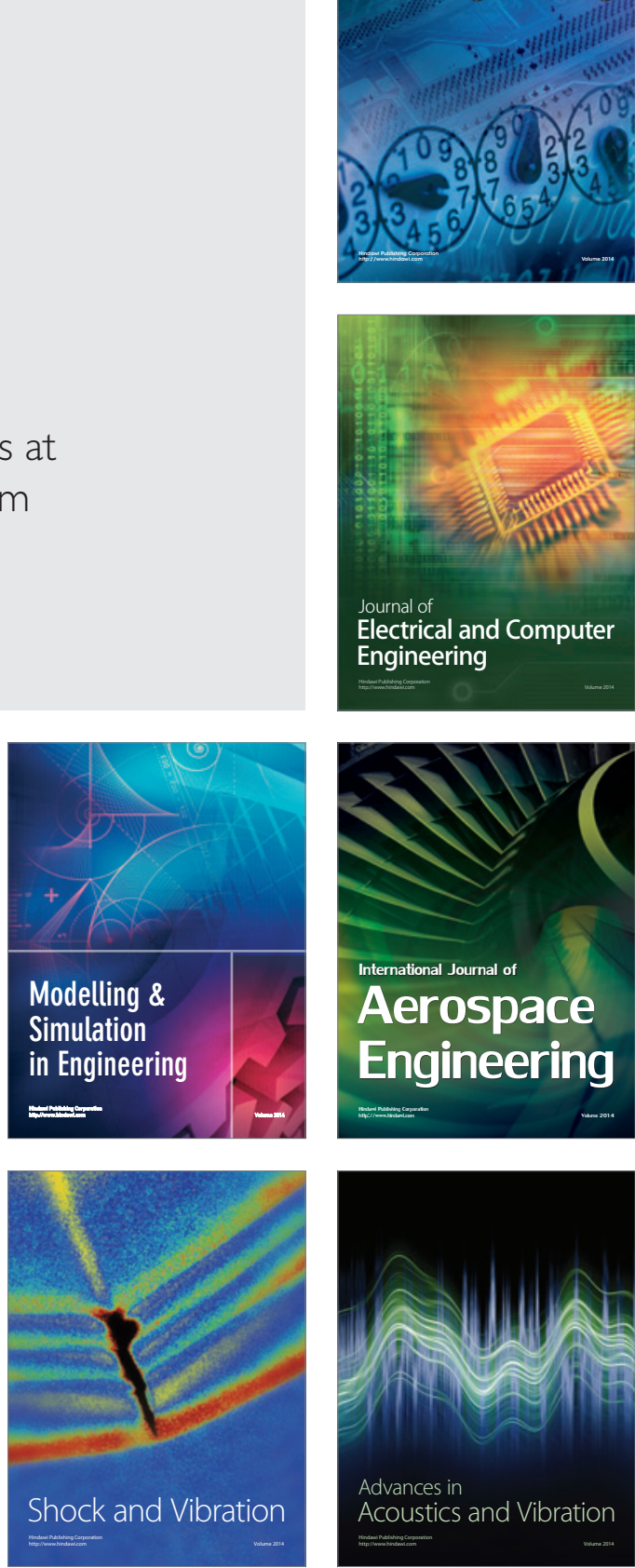